\title{
Minimally Invasive Pericranial Flap for Reconstruction after Endonasal Endoscopic Surgery of 30 Consecutive Patients
}

\author{
Joel Caballero-García1* ${ }^{*}$ Iosmill Morales Pérez , Adolfo Michel Giol Álvarez², \\ Nélido Gonzáles Fernández¹, Bismark Rafael Barcia Sánchez¹, Roxana Bethzave Ortega Pineda1 \\ ${ }^{1}$ National Institute of Oncology and Radiobiology, Havana, Cuba \\ ${ }^{2} J u a n$ Manuel Márquez Pediatric Hospital, Havana, Cuba \\ Email: *joelcg@infomed.sld.cu
}

How to cite this paper: Caballero-García, J., Pérez, I.M., Álvarez, A.M.G., Fernández, N.G., Sánchez, B.R.B. and Pineda, R.B.O. (2018) Minimally Invasive Pericranial Flap for Reconstruction after Endonasal Endoscopic Surgery of 30 Consecutive Patients. International Journal of Otolaryngology and Head \& Neck Surgery, 7, 199-208. https://doi.org/10.4236/ijohns.2018.74021

Received: April 24, 2018

Accepted: July 23, 2018

Published: July 26, 2018

Copyright $\odot 2018$ by authors and Scientific Research Publishing Inc. This work is licensed under the Creative Commons Attribution International License (CC BY 4.0).

http://creativecommons.org/licenses/by/4.0/

\begin{abstract}
Objectives/Hypothesis: The introduction of intranasal pedicled flaps has reduced the incidence of postoperative cerebrospinal fluid (CSF) leaks to less than $5 \%$. Nevertheless, in malignant tumors those flaps are not always available because of nasal septum invasion. Minimally invasive pericranial flaps (PCF) are associated with minimal adverse effects and good cosmetic appearance. In spite of that, there are only a few reports of this reconstructive technic limited to short surgical series and radio-anatomical analysis. Clinical results of a surgical cohort are presented. Study Design: Cohort prospective study. Methods: Clinical data, including age, gender, stage, histopathological findings, rate of complications and appearance of PCF at fifth day and two months postoperative were recorded. Postoperative morbidities were recorded as wound abnormalities, nasosinusal, orbital and central nervous system complications. Chi-squared test was used to correlate qualitative variables and Student-t-test to correlated qualitative and quantitative variables. Items were considered statistically significant with a $\mathrm{p}$ value of less than 0.05 (confidence Interval of 95\%). Results: Thirty patients (18 males and 12 females) were registered. Mean age was 51.5 years \pm 23.0 and range between 20 and 71 years. The most common histological subtypes were scamous cell carcinoma and adenocarcinoma. Complete resection of the tumor was achieved in all patients including surgical margins. Length of the PCF varies between $9.9 \mathrm{~cm}$ and 13.9 $\mathrm{cm}$ with a mean of $11.8 \mathrm{~cm}$. There was an association between length of the flaps and the covering structure with the nose apex relation. None patient experienced postoperative cerebrospinal fluid (CSF) leak, frontal sinusitis or other complications. Conclusions: Minimally invasive PCF constitute a good and inexpensive reconstructive option in patients with malignant anterior
\end{abstract}


cranial base tumors in whose nasoseptal flap was not a feasible option.

\section{Keywords}

Minimally Invasive Pericranial Flap, Anterior Cranial Base, Reconstruction

\section{Introduction}

Historically, one of the most important complications after surgery of anterior cranial base (ACB) tumors was cerebrospinal fluid (CSF) leak. The introduction of intranasal pedicled flaps (ultimately nasoseptal flap) [1] has reduced the incidence of postoperative CSF leaks to less than 5\% [2]. Nevertheless, in malignant tumors those flaps are not always available because of nasal septum invasion. A number of pedicled regional flaps have been proposed for ACB reconstruction including minimally invasive pericranial flap (PCF) [3] and facial artery buccinatory flap [4]. The last one of them is associated with limited pedicle mobility, high donor site morbidity and potential trismus. On the other hand, minimally invasive PCF are associated with minimal adverse effects, good cosmetic appearance and have the largest area of coverage of all alternative regional flaps [5]. A number of dural substitutes are available for ACB reconstruction as dehydrated human pericardium (Tutoplast, Tutogen Medical GmbH); collagen matrix (Duragen, Integra LifeSciences Corp.). On the other hand, there are different surgical glues which are applied during the extended approaches to fill the surgical cavities: fibrin glue (Tisseel, Baxter BioSciences) and semisynthetic glue composed of purified bovine serum albumin and glutaraldehyde (BioGlue, CryoLife, Inc.) [6]. However, these materials are expensive, especially in undeveloped countries. In spite of that, there are only a few reports of minimally invasive PCF limited to short surgical series and radio-anatomical analysis [3]-[9]. Authors don't found any paper relative to this technic in undeveloped countries.

The purpose of our publication is to reflect our experience, the usefulness of the method as well as performing some considerations about the technique.

\section{Methods}

A prospective cohort study was performed of 30 consecutive patients with advanced malignancies of ACB treated by means expanded endonasal endoscopic approach and minimally invasive PCF for ACB defect reconstruction at the National Institute of Oncology and Radiobiology in Cuba from January 2016 to June 2017.

Inclusion criteria include: patients with malignant nasosinusal tumors of anterior cranial base confirmed by preoperative biopsy with nasal septum involvement (in CT scan or RMI images) or when it is suspected because off the adjacent tumor (during surgical inspection). Sample selection includes all patients who underwent minimally invasive PCF during the mentioned time interval. 
Clinical data, including age, gender, stage (according to the tumor, node, and metastases (TNM) staging system for nasal cavity and ethmoid sinus malignancy of the American Joint Committee on Cancer (AJCC)) [10], histopathological findings, rate of complications and appearance of PCF at fifth and 2 months postoperative days were recorded. Postoperative morbidities were recorded as wound abnormalities, nasosinusal, orbital and central nervous system complications.

Length of the flaps was measured from the nasion to the midpoint end.

Prior and 2 months before to surgery, the evaluation included high-resolution Computed Tomography Scan and Magnetic Resonance Imaging.

\section{Surgical Technique}

The operative technique for endoscopic resection o ACB malignancies has been previously described [11] [12]. In all cases a Draft III procedure (Lothrop modified procedure) was performed in order to prevent frontal sinus obstruction causing by the flap. Minimally invasive PCF was performed in the first six cases using a previously described two galeal port incisions of $2 \mathrm{~cm}$, but in the rest 24 cases a single $4 \mathrm{~cm}$ incision in alignment with a coronal incision centered in the middle pupil line was performed (Figure 1(A)). Previously a limited hair area was shaved. A $1 \mathrm{~cm}$ horizontal right glabellar incision was performed as previously described [3] until the nasion and lacrimal bones were exposed.

An endoscopic dissection of the subgaleal plane (Figure 1(C) and Figure 2(A)) was performed using a four hand-two surgeon technic (Figure 1(B)) through galeal and glabellar incisions to the level of the right orbital rim. Subgaleal dissection was exended posterior to the coronal plane as far as possible to increase the length of the flap. Using a monopolar with a needle tip curved 90 grades the pericranium was incised beginning with the medial sagittal, lateral sagittal and lastly posterior transversal incision. Them, the pericranial flap were elevated until superior orbital rim carefully in order to do not perforate it. A periosteal elevator introducing through glabellar incision was particularly useful during this step. As previously described a horizontal $4 \mathrm{~mm} \times 1.5 \mathrm{~cm}$ osteotomy was performed at the level of the nasion. A curved ostium explorator was used to confirm the communication with nasal cavity and the PCF was transposed using endoscopic visualization and carefully flattened to cover the inlay facial graft. A layer or $2 \mathrm{~cm}$ Gelfoam were applied and two Foley balloons, one in front of the choanas, supported the flap and the latest upper assessing a superior-inferior direction of the enlargement in order to do not mobilized the flap. Galeal incision was closed using a 2.0 nylon suture and glabellar incision using a 5.0 chromic suture and nylon 3.0 in an intradermic fashion. All patients were extubated in the operation room and were observed one night in the Intensive Care Unit.

Lumbar spinal drain was not used.

Statistical analyses were computed using SPSS Version 20.0; Chi-squared test 


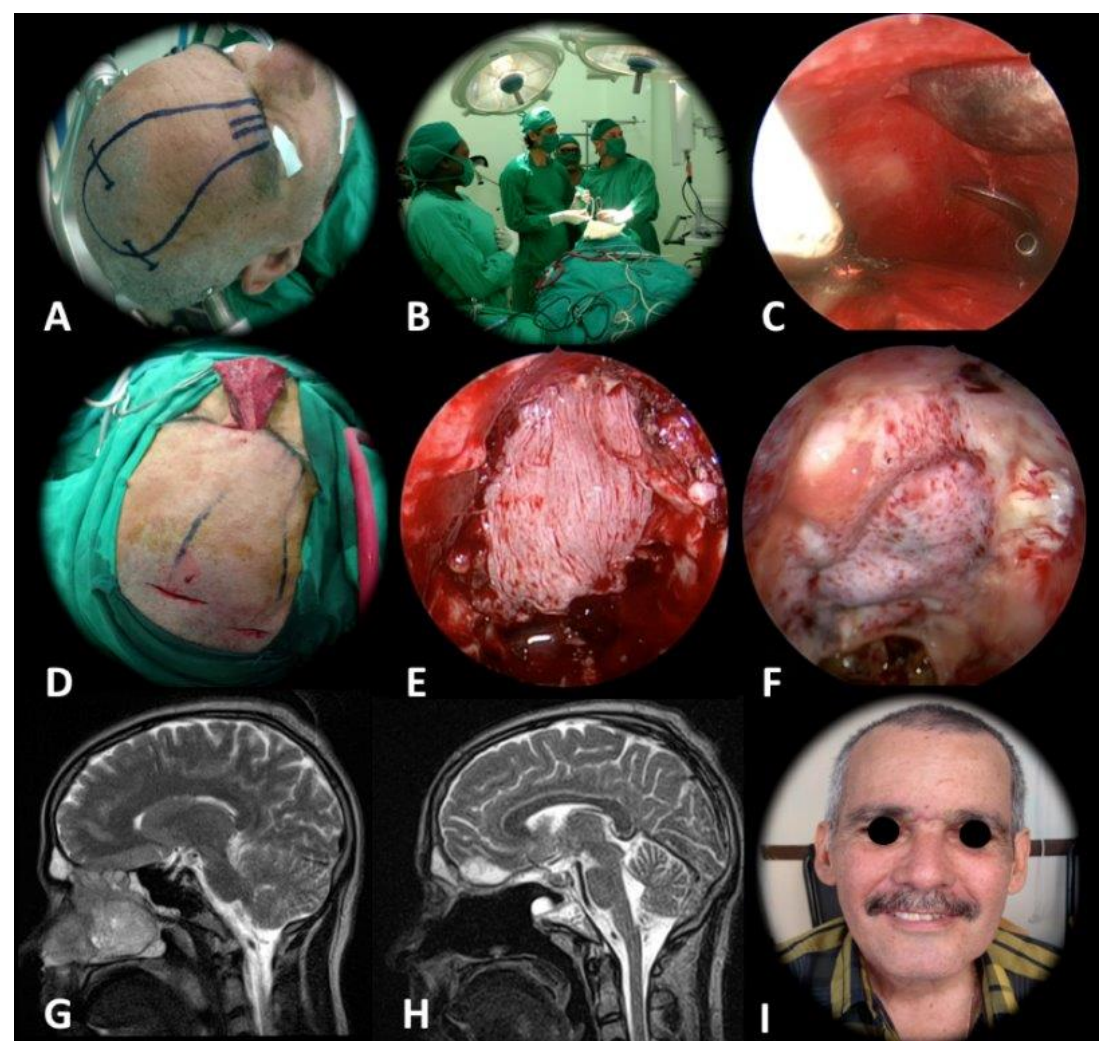

Figure 1. Patient number 3 with an esthesioneuroblastoma. (A) the pedicle is marked along the right supraorbital rim $(3 \mathrm{~cm}$ wide) and $2-\mathrm{cm}$ scalp incisions are additionally marked in the coronal plane; (B) both surgeons are situated on the apex of the patient's head; (C) during endoscopic scalp dissection with a four hand-two surgeons technic; (D) two scalp incisions and the exteriorized PCF were observed; (E) PCF covering the anterior cranial base defect; (F) PCF was observed viable and sealed on postoperative day 5; $((\mathrm{G}),(\mathrm{H}))$ pre and postoperative RMI T2 sagittal images showing a total removal of the tumor and the PCF covering the cranial base; (I) postoperative picture of the patient showing a minimal cosmetic deformity.

was used to correlate qualitative variables and Student-t-test to correlated qualitative and quantitative variables. Items were considered statistically significant with a $\mathrm{p}$ value of less than 0.05 (confidence Interval of 95\%).

\section{Results}

Thirty patients (18 male and 12 female) were registered. Mean age was 51.5 years \pm 23.0 and range between 20 and 71 years. Most common histologic subtypes were squamous cell carcinoma and adenocarcinoma. 14 patients have stage III lesions while 16 patients stage IV-A or IV-B (Table 1).

Tumors crossed the midline with nasal septum destruction in 21 patients. In the other 9 nasal septum involvement was suspected due loss of integrity of contralateral mucosa, erosion or tumor extension in to contralateral sphenoethmoidal recess.

Complete resection of the tumor was achieved in all patients including surgical margins (nasal septum, anterior cranial base bone, dura, olfactory bulbs and one 


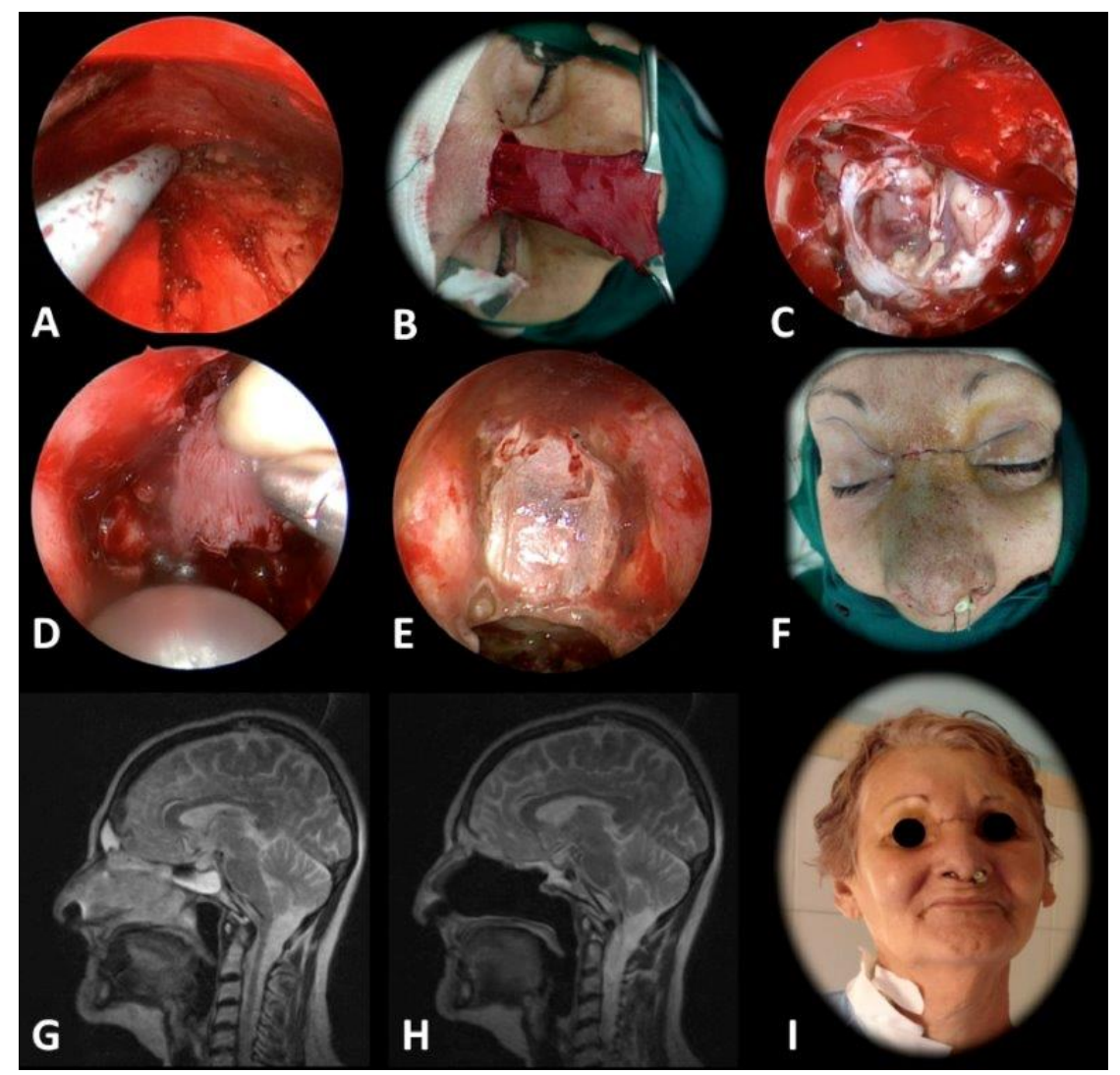

Figure 2. Patient number 29 with a squamous cell carcinoma. (A) during endoscopic PCF performing; (B) an exteriorized flap; (C) anterior cranial base defect after dural removal; (D) both Foley balloons were used to support PCF. Observe that inferior balloon was completely insufflated and superior balloon was placed ensuring a superior-inferior inflation; (E) endoscopic visualization of a viable and sealed PCF at $5 \mathrm{ft}$ post-op day; (F) after glabellar wound closed; ((G), (H)) pre-and postoperative RMI T2 sagittal images showing a total removal of the tumor and the PCF covering the cranial base; (I) postoperative picture of the patient showing a minimal cosmetic deformity.

or both medial orbital walls. Sagittal plane approaches include transcribiform, transcribiform-transplanum and transcribiform-transplanum-transtuberculum approaches ('Table 1 ).

Length of the PCF varies between $9.9 \mathrm{~cm}$ and $13.9 \mathrm{~cm}$ with a mean of $11.8 \mathrm{~cm}$. There was association between length of the flaps and the covering structure with the nose apex relation (Table 2 and Figure 3 ).

All NSF showed viable and sealed on $5 \mathrm{ft}$ and 3 months post-op period (Figure 1(E) \& Figure 1(F) and Figure 2(D) \& Figure 2(E)).

All PCF were viable and sealed at the fifth postoperative day (Figure $1(\mathrm{~F})$ and Figure 2(E)) and at 2 months where completely covered by nasal mucosa. None patient experienced postoperative CSF leak, frontal sinusitis or other complications. Totally patients expressed them satisfy with the reconstruction.

\section{Discussion}

Reconstruction after endonasal endoscopic surgery for cranial base tumors is an 
important stage of these approaches because if it's carried out in a satisfactory manner it may prevents complications as CSF leaks and infections. Implementation of the vascularized nasoseptal flap described by Hadad and Basabasteguey in 2006 [1] has significantly reduced the incidence of postoperative's CSF leaks. However, in malignant tumors of the anterior cranial base, especially in advanced stages, destruction of the nasal septum is commonly present and precludes

Table 1. Clinical and surgical characteristics of the cohort.

\begin{tabular}{|c|c|}
\hline Variable & Value \\
\hline Total no. of patients & 30 \\
\hline male & 18 \\
\hline female & 12 \\
\hline Mean age in years & 51.5 \\
\hline Mean follow-up in months & 6.7 \\
\hline \multicolumn{2}{|l|}{ Histologic subtype } \\
\hline Scamous cell carcinoma & 15 \\
\hline Adenocarcinoma & 9 \\
\hline Esthesioneuroblastoma & 4 \\
\hline Renal metastases & 1 \\
\hline Rhabdomyosarcoma & 1 \\
\hline \multicolumn{2}{|l|}{ Stage } \\
\hline III & 14 \\
\hline IV-A & 11 \\
\hline IV-B & 5 \\
\hline \multicolumn{2}{|l|}{ Surgical approach } \\
\hline transcribiform & 12 \\
\hline transcribiform-transplanum & 5 \\
\hline transcribiform-transplanum-transtuberculum & 13 \\
\hline
\end{tabular}

Table 2. Minimally invasive PCF relative variables.

\begin{tabular}{|c|c|c|c|}
\hline \multirow{2}{*}{ Covering structure } & \multicolumn{2}{|c|}{ Relation with the nose apex } & \multirow{2}{*}{$\mathrm{p}$} \\
\hline & At the level & Exceeded the level & \\
\hline Cribiform plate & 9 & - & \multirow{4}{*}{$<0.001^{\star}$} \\
\hline Planum & 2 & - & \\
\hline Tuberculum & - & 13 & \\
\hline Sellar floor & - & 6 & \\
\hline \multicolumn{4}{|l|}{ Length of the flap $(\mathrm{cm})$} \\
\hline $11.8(1.2)^{* *}$ & $10,7(0.9)$ & $12.9(0.7)$ & $<0.001^{* * *}$ \\
\hline
\end{tabular}

${ }^{\star}$ Chi-squared test. CI $95 \% .{ }^{* *}$ Values expressed as the "mean" and "standard mean deviation". ${ }^{* * * S t u d e n t ' s}$ t-test. CI 95\%. 


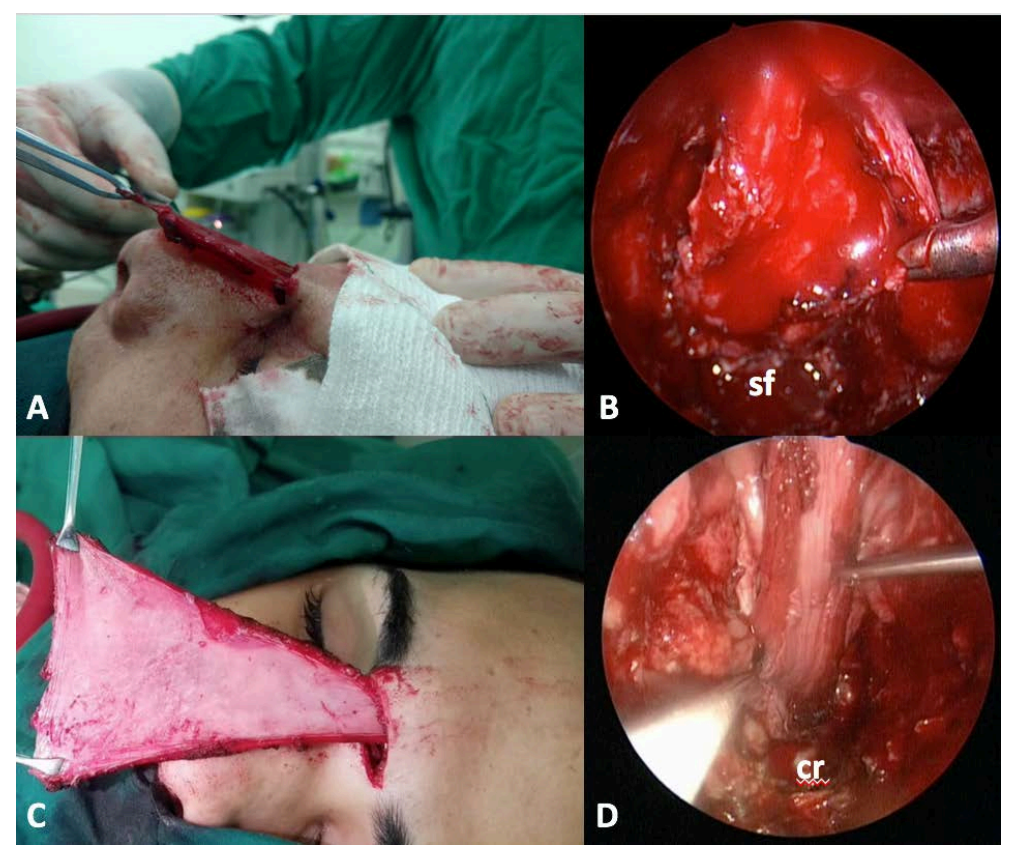

Figure 3. A comparison between patients 7 and 18. The first ((A), (B)) with a flap that do not exceeded nose apex and only covered sphenoidale planum and the second ((C), (D)) with a longer flap that extended to cover sellar floor.

the realization of this flap. In the best of cases the septum is considerably displaced and its proximity to the lesion makes its resection necessary within the oncology margins.

Historically the PCF has been used in the reconstruction after craniofacial surgery for malignant tumors of the anterior cranial base [13]. Zanation et al. [3] in 2009 described a technique for obtaining a PCF by minimal invasive techniques after endonasal endoscopic surgery. However, up to date a scarce number of articles have been published [3] [8] [9] [14]. This technic has been so called "money box" [8] or "mailbox slot" [9] approaches due the needed of a horizontal nasionectomy to introduce the flap.

PCF have some advantages: it constitutes a vascularized flap; has the largest area of coverage; there are not risk of postoperative mucocele; it can be covered with a nasoseptal flap in extensive defects. For that reason, it is considerate the most versatile alternative to the nasoseptal flap [9]. In a radio-anatomical analisis performed by Patel et al. [14] demostrated that PCF can cover the skull base as far posteriorly as the sella. Other radio-antomical study performed by Santamaria et al. [8] demostrated that PCF renders enough tissue to reconstruct all defects in the ventral skull base, including the clivus. The length of PCF was between 10.6 and $13.1 \mathrm{~cm}$, similary to this study with a mean of $11.8 \mathrm{~cm}$.

Santamaria et al. [8] established a relation between the external ear canal and the length of the PCF in the midsagital plane CT reconstruction. They conclude that to reconstruct satisfactory a transcribiform defect, the PCF distal incision should be carried at approximately $4 \mathrm{~cm}$ (angle $20^{\circ}$ ) from the vertical projection of the external ear canal on the skull. From another point of view, this study 
showed that there is relation between the nose apex and the area covered by the PCF. If PCF exceded the nose apex, it will cover the sellar floor. Despite Sanamaria et al. method is more quantitative, and facilitated the preoperatory measurement and plan, our method should be complementary to estimate the covering area by the flap before introduce in the nose cavity.

In a large retrospective studio Patel and cols. [7] founded that $10 \%$ of patients that undergone endoscopic endonasal skull base reconstructions lacked NSF availability. We have found a bigger percentage of these patients probably because in our tertiary center we receive with high frequency patients with very advanced lesions or with failed previous surgeries in other centers. Otherwise, limitations of diagnostic resources conduce to a diagnoses delay like in many other underdeveloped countries. Other reconstructive alternatives like inferior turbinate flap are not a feasible option because they are limited to a small defect. On the other hand, heterologous materials and tissue sealants are expensive for underdeveloped countries.

\section{Considerations about Surgical Technic and Practical Aspects}

Despite surgical technic to obtain a minimally invasive PCF have been well documented, there are some practical aspects that we want to make emphasis and aggregate to the original technic described:

First, galeal incisions should locate in the transition between the coronal plane of the forehead and the axial plane of the vertex to optimize the use of the monopolar. If not so could not reach the distal pericranium.

A single incision of $4 \mathrm{~cm}$ replaces very well the previously described two incisions of 2 and $1.5 \mathrm{~cm} \mathrm{[3],} \mathrm{it} \mathrm{is} \mathrm{theoretically} \mathrm{more} \mathrm{fast} \mathrm{and} \mathrm{comfortable,} \mathrm{resulting}$ in only a wound and not two wounds. During the pericranial flap performance we recommended to first beginning by incision in mediosagital plane, them in laterosagital plane and finally in the rear. It facilitates subsequent dissection, as the previously uninserted pericranium not hinders.

The reconstruction time should be done at the end and it's the last step. It is true that more serious logical would be do first clean surgery and then do the not clean procedure, but that guaranteeing to a dewatering of the flap. On the other hand, sometimes the decision to make a nasoseptal flap or not is based on transoperative findings (infiltrated septum). Not be found complications with doing this procedure at the end of the surgery. Gloves and robe substitution after nasal step is crucial to avoid infections.

PCF is not uninserted until the steps of entering the nasal cavity for it not desiccated.

The nasionectomy should be fair to the flap so neither that nor the extrangule nor is free space which can promote nasal secretions flow to the forehead subgaleal space.

It's crucial to take care not to twist the flap, for this is useful the endoscopic assistance during exteriorization of the same thought the glabellar incision. 
Always a Draft III should be performed, now, in small frontal sinuses is suggested to perform a front osteoplasty (total occlusion of sinuses) to prevent sinusitis. That why preoperative imaging evaluation of sinuses is critical. We did not find any patient with this feature.

We use two Foley balloons, and recommend to first inflate the balloon at the bottom front the choanas, then it's superior portion must be inflate in a direction from top to bottom to make it go in favour of the flap (unlike in the case of a nasoseptal flap). In case of dispose of tissue adhesives, it could be dispensed with balloon offering greater patient comfort.

When inflating the balloon, it must be careful not to compress the pedicle against the back wall of the frontal sinus too so not be necrose.

The pedicle can' $t$ be very wide because it hinders the opening of the flap (accordion effect), it can be useful once placed over the defect bone from the cranial base make small cuts on both sides of the pedicle in order to expands it better.

We have seen that it is sufficient to cover all the defects of the cranial base (from orbit to orbit and from frontal sinus to the suprasellar notch and even the sellar floor).

We do not find postoperative hematomas in any of our patients despite we not use subgaleal drainage but we do not advise against this practice.

Lumbar drainage is probably unnecessary due the PCF effectiveness and can increase the risk of tension pneumocephalus.

None of our patients presented postoperative CSF leak, frontal sinus disease or cosmetic complications in the postoperative time, similarly to other authors [6] [7].

There are some limitations of this study. Although it contains the major sample reported of minimally invasive PCF its cohort design is inadequate to archive more data of this technique. Randomized comparative trials with other ACB reconstruction techniques and long-term studies will be usefully.

\section{Conclusion}

Minimally invasive PCF constitute a good and inexpensive reconstructive option in patients with malignant anterior cranial base tumors in whose nasoseptal flap was not a feasible option.

\section{References}

[1] Hadad, G., Bassagasteguy, L., Carrau, R.L., Mataza, J., Kassam, A., Snyderman, C.H., et al. (2006) A Novel Reconstructive Technique after Endoscopic Expanded Endonasal Approaches: Vascular Pedicle Nasoseptal Flap. Laryngoscope, 116, 1882-1886. https://doi.org/10.1097/01.mlg.0000234933.37779.e4

[2] Kassam, A.B., Thomas, A., Carrau, R.L., Snyderman, C.H., Vescan, A., Prevedello, D., et al. (2008) Endoscopic Reconstruction of the Cranial Base Using a Pedicled Nasoseptal Flap. Neurosurgery, 63, 44-52. https://doi.org/10.1227/01.NEU.0000297074.13423.F5

[3] Zanation, A.M., Snyderman, C.H., Carrau, R.L., Kassam, A.B., Gardner, P.A. and 
Prevedello, D.M. (2009) Minimally Invasive Endoscopic Pericranial Flap: A New Method for Endonasal Skull Base Reconstruction. Laryngoscope, 119, 13-18. https://doi.org/10.1002/lary.20022

[4] Rivera-Serrano, C.M., Oliver, C.L., Sok, J., et al. (2010) Pedicled Facial Buccinator (FAB) Flap: A New Flap for Reconstruction of Skull Base Defects. Laryngoscope, 120, 1922-1930. https://doi.org/10.1002/lary.21049

[5] Kim, G.G., Hang, A.X., Mitchell, C.A. and Zanation, A.M. (2013) Pedicled Extranasal Flaps in Skull Base Reconstruction. Advances in Oto-Rhino-Laryngology, 74, 71-80. https://doi.org/10.1159/000342282

[6] Cavallo, L.M., Messina, A., Esposito, F., de Divitis, O., del Fabro, M. and Esposito, F., et al. (2007) Skull Base Reconstruction in the Extended Endoscopic Transsphenoidal Approach for Suprasellar Lesions. Journal of Neurosurgery, 107, 713-720. https://doi.org/10.3171/JNS-07/10/0713

[7] Patel, M.R., Taylor, R.J., Hackman, T.G., Germanwala, A.V., Sasaki-Adams, D., Ewend, M.G., et al. (2016) Beyond the Nasoseptal Flap: Outcomes and Pearls with Secondary Flaps in Endoscopic Endonasal Skull Base Reconstruction. Laryngoscope, 124, 846-852. https://doi.org/10.1002/lary.24319

[8] Santamaría, A., Langdon, C., López-Chacon, M., Cordero, A., Enseñat, J., Carrau, R., et al. (2017) Radio-Anatomical Analysis of the Pericranial Flap "Money Box Approach" for Ventral Skull Base Reconstruction. The Laryngoscope, 127, 2482-2489. https://doi.org/10.1002/lary.26574

[9] Majer, J., Herman, P. and Verillaud, B. (2016) "Mailbox Slot" Pericranial Flap for Endoscopic Skull Base Reconstruction. Laryngoscope, 126, 1736-1738. https://doi.org/10.1002/lary.25686

[10] (2017) National Comprensive Cancer Network. Version 2.2017.

[11] Castelnuovo, P., Battaglia, P., Turri-Zanoni, M., Tomei, G., Locatelli, D., Bignami, M., et al. (2014) Endoscopic Endonasal Surgery for Malignancies of the Anterior Cranial Base. World Neurosurg, 82, 22-31. https://doi.org/10.1016/j.wneu.2014.07.021

[12] Snyderman, C.H., Carrau, R.L., Kassam, A.B., Zanation, A., Prevedello, D., Gardner, P., et al. (2008) Endoscopic Skull Base Surgery: Principles of Endonasal Oncological Surgery. Journal of Surgical Oncology, 97, 658-664. https://doi.org/10.1002/jso.21020

[13] Hatano, T., Motomura, H. and Ayabe, S. (2015) Reconstruction Using Locoregional Flaps for Large Skull Base Defects. Journal of Neurological Surgery-Part B, 76, 167-170. https://doi.org/10.1055/s-0034-1390397

[14] Patel, M.R., Shah, R.N., Snyderman, C.H., Carrau, R.L., Germanwala, A.V., Kassam, A.B., et al. (2010) Pericranial Flap for Endoscopic Anterior Skull-Base Reconstruction: Clinical Outcomes and Radioanatomic Analysis of Preoperative Planning. Neurosurgery, 66, 506-512. https://doi.org/10.1227/01.NEU.0000365620.59677.FF 